\title{
Developing an Effective Employee Performance Appraisal System
}

\author{
Nnanna, Emmanuel E. \\ Ebonyi State University \\ Abakaliki, Nigeria
}

\author{
Ugha John O. \\ Ebonyi State University \\ Abakaliki, Nigeria
}

\begin{abstract}
This study focuses on developing an effective employee performance appraisal system and employees' perception of justice with the appraisal outcome. The study tries to identify the various techniques used in the appraisal process, the error(s) associated with each technique, all known metrics of performance measurement, and best ways of capturing appraisal data. This study is imperative in view of the fact that most existing appraisal system limit staff performance to competence only. The current system uses generic ratings for all workers irrespective of their job roles and do not employ biometrics in the appraisal process. Leveraging on the potentials of information and communications technology (ICT) helps to harmonize all issues embedded in the current appraisal system. Data was collected from both primary and secondary sources in order to elicit information from stakeholders. Some hypotheses were adopted. Questionnaires were also used to help in data collection from both stake holders and workers in general. Hypothesises were tested using chi-square with degree of freedom (d.f.) $=(n-1)=4$ and level of significance $(\alpha)$ is 0.05 . Pie chart was also use in the analysis. Results show that there is a high level of perception of injustice with the present appraisal system by stakeholders. Result also shows that existing appraisal systems limits workers performance to competence only. It was revealed that an effective appraisal system should be technology-driven. Technology-driven employee performance appraisal system utilizes all known matrices of performance measurement in the appraisal process. This approach to workers appraisal would bring about transparency and efficiency in the system. It would also bring about wide participation in the appraisal process. Furthermore, it would create room for increased productivity, proper monitoring of workers performance and increased workers satisfaction.
\end{abstract}

Keywords: Technology-driven, employee-performance, appraisal, effective, measurement appraisal outcome

\section{INTRODUCTION}

Performance appraisal has received the attention of several authors over the years. Palaiologos et al. [1] defined performance appraisal as a methodical process of identifying, observing, measuring, recording and developing the jobrelevant strengths and weaknesses of employees. Performance appraisal can be describes as the procedures adopted by an organization in order to improve an individual's performance through evaluation, feedback, merit increments, and promotions [2]. Performance appraisal is the system used by an organization to assign a score indicating the performance of an individual or a group [3]. Performance appraisal is the process of evaluating or judging the way in which someone is functioning [4]. The practice of performance appraisal is a mandated process in which, for a specific period of time, all or a group of employees' work performance, behaviour, or traits are individually rated, judged, or described by a person other than the rated employee and the results are kept by the organization [4]. The practice of giving employees annual ratings or performance evaluation is widely accepted as an essential and valuable tool throughout the business world [5]. From the above definitions, performance appraisal suggests a system of measurement. If we believe that appraising means measuring, then we will try to improve our appraisal of performance by measuring more precisely [6]. Human performance, except in such terms as things produced per hour, cannot be measured precisely. On the other hand, an excuse that some jobs cannot be described objectively is either ill-informed or deliberate. Although some job performance cannot be "counted" in numeric terms, whether or not performance achieves expectations can be assessed [6]. However, the question still remains 'what should be measured?' put differently, 'what should be the source of appraisal data?' and 'how should it be measured and processed?' In an attempt to answer these knotty questions, several scholars and practitioners alike have suggested and adopted the use of the following appraisal systems: Comparison or ranking methods (includes: straight ranking, alternation ranking, paired comparisons, forced distribution), standards-based reviews (includes: critical incidents, essays and narrative appraisals, checklists, forced choice, rating scales, behaviourally anchored rating scales (BARS), behavioural observation scales (BORS)), result-oriented reviews (management by objectives (MBO), and competencybased methods. These systems are collectively called traditional systems of appraisal [7] and they are judgmental in nature and prone to psychometric errors - errors in measurement that occur because of the psychological predisposition or make-up of the assessor [8]. The unfortunate fact about psychometric errors is that most assessors are not aware that they are liable to such errors [8]. As a result of the psychometric errors inherent with the traditional systems, several researchers came up with automated systems of appraisal. These systems include but are not limited to Analytic Hierarchy Process (AHP)-based [9] evaluating process based on weighted criteria to combat such problems as favouritism and prejudice associated with the traditional system. This system remains partially manual and is heavily reliant on the Human Resource Department's willingness to cooperate; Internet of Things (IoT) based [10] systems that makes use of Internet of Things (IoT) based systems to automatically gather accurate data that feeds into an evaluation algorithm. However, there was no way of measuring employee's daily task output and competency skills. The system merely calculates employees' performance based on data from clock in and clock out registers; A Game Theoretic Appraisal for an IoT-Based Automatic Employee Evaluation [11] which proposes a game theoretic approach for 
an Internet of things (IoT) based performance evaluation of the employees in industry. IoT is a new paradigm that interconnects the various "objects" through sensor devices, Radio-frequency identification (RFID) scanners, actuators, and other wireless and mobile devices. This system has some flaws, firstly, assessments of employees are not based on competency skills and the system also fails to capture employees' daily tasks outputs as part of performance appraisal, secondly, there is no discrete ranking of employees' work output and organizational behaviours as to determine the highest scored employee and the lowest scored employee within a given assessment period; and Fuzzy Based appraisal systems [12]. The fuzzy system has its own flaws which include but not limited to the fact that fussy systems are not based on measurable task outputs but on fuzzy or crisp qualitative employee appraisal skills and so do not measure a critical part of modern organizational performance criteria. Recently, more flexible online appraisal systems have emerged. These systems include but not limited to: Trakstar appraisal software, BambooHR software, Ultipro appraisal software and workday performance appraisal software. However, these online appraisal systems not only limited their performance measures to competencies only, they also used generic ratings for all workers irrespective of their roles or positions within their organizations. The online appraisal systems did not consider also the smart application of biometrics in securing appraisal data. This approach overlooked some important performance criteria that were relevant to particular jobs, and included other criteria that were irrelevant to others. In order to overcome the challenges associated with the current appraisal systems, there is a need: to develop a technology-driven appraisal system that can utilize an expanded range of performance tools to capture data from all known sources of appraisal information, and in quality time too; to develop a system that does not use generic rating across board but one that uses both core organizational competencies and job family competencies captured through the popular 360-degree appraisal method; to develop a system that employs smart application of biometrics in the appraisal process in order in order to give validity to the instrument of performance measurement and protect the integrity of the appraisal data.

\section{METHODS}

The study utilized survey research design to obtain relevant data. Three hypotheses were postulated to guide us in the work. The method of research involved administering of questionnaires and subsequent analysis of the results of the questionnaires using chi-squared goodness of fit tests. The results obtained from the chi-squared analysis were used to test the hypotheses.

\subsection{Hypotheses}

To guide our work in this study, the following hypotheses were posited.

i. There is significant relationship between use of traditional appraisal system and low level of employees' perception of organizational justice.

ii. There is significant relationship between technology-driven appraisal system with multi-sourced appraisal data and high level of employees' job satisfaction.

iii. Use of technology-driven appraisal system minimizes errors in the appraisal process.

\subsection{Source of Data}

We studied "Developing an Effective Employee Performance Appraisal System" with data from two main sources thus:

Primary Source: Questionnaires were used to obtain relevant data from stakeholders in three public sector agencies of Nigeria. A total of 152 questionnaires covering 5 questions were delivered by hand to the stakeholders in these agencies. Out of this number, 148 questionnaires were completed and returned. The questions sought, among others, the views of the respondents on the relationship between the use of traditional appraisal system and employees' perception of organizational justice.

Secondary Source: Relevant information was drawn from articles and books written by professionals in the Human Resource and IT industries.

\subsection{RESULTS}

\subsection{Data Analysis and Result Presentation}

Quantitative data obtained from primary source were analyzed using the chi-squared test. Table 2 and figure 3 both show the level categorizations of respondents. Table 1 shows the questions, responses and $\mathrm{X}^{2}$ values from the chi-squared analysis of the questionnaires.

Table 1. Categorization of respondents

\begin{tabular}{|l|l|l|l|}
\hline S/n & $\begin{array}{l}\text { Respondents' } \\
\text { category }\end{array}$ & Number & Percentage \\
\hline $\mathbf{1}$ & Junior staff & $\mathbf{6 6}$ & $48.33 \%$ \\
\hline $\mathbf{2}$ & Senior staff & $\mathbf{6 0}$ & $41.67 \%$ \\
\hline $\mathbf{3}$ & $\begin{array}{l}\text { Management } \\
\text { staff }\end{array}$ & $\mathbf{2 2}$ & $10.00 \%$ \\
\hline & Total: & $\mathbf{1 4 8}$ & $\mathbf{1 0 0 . 0 0 \%}$ \\
\hline
\end{tabular}

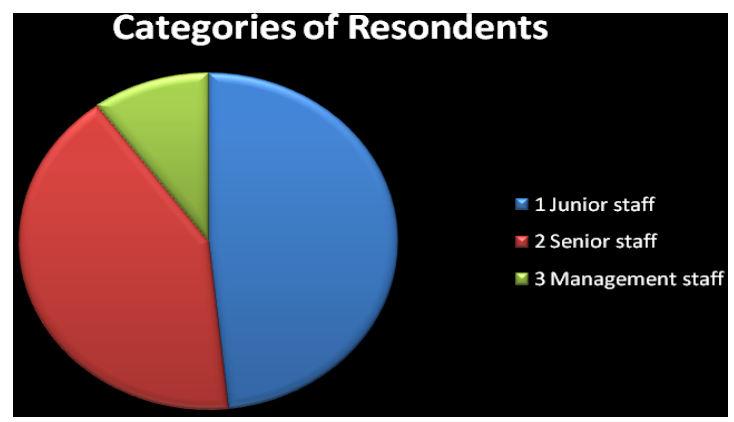

Figure 1. Pie Chart showing level categorization of employees 
Table 2. Questions, responses and $x^{2}$ values from the chisquared analysis

\begin{tabular}{|c|c|c|c|c|c|}
\hline $\mathbf{S} / \mathbf{n}$ & Question & $\mathbf{O}_{\mathrm{i}}$ & $\mathbf{E}_{\mathrm{i}}$ & $\left(\mathbf{O}_{\mathrm{i}}-\mathbf{E}_{\mathrm{i}}\right)^{2} / \mathbf{E}_{\mathrm{i}}$ & $\begin{array}{l}\mathbf{X}^{2}= \\
\left.\sum\left[\mathbf{O}_{i}-\mathbf{E}_{\mathrm{i}}\right)^{2} / \mathbf{E}_{\mathrm{i}}\right]\end{array}$ \\
\hline 1. & $\begin{array}{l}\text { The use of } \\
\text { traditional } \\
\text { appraisal system } \\
\text { leads to low level } \\
\text { of employees' } \\
\text { perception of } \\
\text { organizational } \\
\text { justice } \\
\text { - SA } \\
\text { - A } \\
\text { - U } \\
\text { - D } \\
\text { - SD }\end{array}$ & $\begin{array}{l}112 \\
24 \\
0 \\
8 \\
4\end{array}$ & $\begin{array}{l}29.6 \\
29.6 \\
29.6 \\
29.6 \\
29.6\end{array}$ & $\begin{array}{l}229.38 \\
1.06 \\
29.6 \\
15.76 \\
22.14\end{array}$ & 297.94 \\
\hline 2. & $\begin{array}{l}\text { The use of } \\
\text { technology- } \\
\text { driven appraisal } \\
\text { process } \\
\text { minimizes errors } \\
\text { in the appraisal } \\
\text { process. } \\
\text { - SA } \\
\text { - A } \\
\text { - U } \\
\text { - D } \\
\text { - SD }\end{array}$ & $\begin{array}{l}116 \\
28 \\
0 \\
2 \\
2\end{array}$ & $\begin{array}{l}29.6 \\
29.6 \\
29.6 \\
29.6 \\
29.6\end{array}$ & $\begin{array}{l}252.19 \\
0.09 \\
29.6 \\
25.74 \\
25.74\end{array}$ & 333.36 \\
\hline 3. & $\begin{array}{l}\text { Employees are } \\
\text { more satisfied } \\
\text { with their job } \\
\text { when } \\
\text { technology- } \\
\text { driven appraisal } \\
\text { system is used } \\
\text { - SA } \\
\text { - A } \\
\text { - U } \\
\text { - D } \\
\text { - SD }\end{array}$ & $\begin{array}{l}118 \\
12 \\
0 \\
10 \\
8\end{array}$ & $\begin{array}{l}29.6 \\
29.6 \\
29.6 \\
29.6 \\
29.6\end{array}$ & $\begin{array}{l}264.01 \\
10.46 \\
29.6 \\
13.5 \\
16.67\end{array}$ & 248.34 \\
\hline 4. & $\begin{array}{l}\text { Appraisal data is } \\
\text { more secured and } \\
\text { reliable with } \\
\text { computer-based } \\
\text { online appraisal } \\
\text { process } \\
\text { - SA } \\
\text { - A } \\
\text { - U } \\
\text { - D } \\
\text { - SD }\end{array}$ & $\begin{array}{l}122 \\
14 \\
6 \\
4 \\
2\end{array}$ & $\begin{array}{l}29.6 \\
29.6 \\
29.6 \\
29.6 \\
29.6\end{array}$ & $\begin{array}{l}288.44 \\
8.22 \\
18.82 \\
22.14 \\
25.74\end{array}$ & 363.36 \\
\hline 5. & $\begin{array}{l}\text { An effective } \\
\text { appraisal system } \\
\text { should be } \\
\text { technology- } \\
\text { based, multi- } \\
\text { sourced data, } \\
\text { multi-rated, } \\
\text { secured and } \\
\text { reliable. } \\
\text { - SA } \\
\text { - A } \\
\text { - U } \\
\text { - D } \\
\text { - SD }\end{array}$ & $\begin{array}{l}114 \\
32 \\
0 \\
0 \\
2\end{array}$ & $\begin{array}{l}29.6 \\
29.6 \\
29.6 \\
29.6 \\
29.6\end{array}$ & $\begin{array}{l}240.65 \\
0.19 \\
29.6 \\
29.6 \\
25.74\end{array}$ & 325.78 \\
\hline
\end{tabular}

\subsection{Test of Hypotheses}

\subsubsection{Hypothesis one}

$\mathrm{H}_{0}$ : There is significant relationship between use of traditional appraisal system and low level of employees' perception of organizational justice.

$\mathrm{H}_{1}$ : There is no significant relationship between use of traditional appraisal system and low level of employees' perception of organizational justice

Relevant in testing hypothesis one is question 1 of the questionnaire.

From the chi-squared analysis in table $2, \mathrm{X}^{2}=\left[\left(\mathrm{O}_{\mathrm{i}}-\mathrm{E}_{\mathrm{i}}\right)^{2} / \mathrm{E}_{\mathrm{i}}\right]$ for question 1 is $\mathbf{2 9 7 . 9 4}$

Our degree of freedom (d.f.) $=(n-1)=4$ and our level of significance $(\alpha)$ is 0.05

\section{Decision}

Tabulated value of $\mathrm{X}^{2}\left(\mathrm{X}^{2} \mathrm{Tab}\right)$ at 4 d.f. and 0.05 level of significance $=\mathbf{9 . 4 8 8}$

The Calculated value of $X^{2}\left(X^{2} \mathrm{Cal}\right)=\mathbf{2 9 7 . 9 4}$

$\mathrm{X}^{2} \mathrm{Cal}>\mathrm{X}^{2} \mathrm{Tab}$

The decision rules states that if $\mathbf{X}^{\mathbf{2}} \mathbf{C a l}$ is greater than $\mathbf{X}^{\mathbf{2}} \mathbf{T a b}$, we should reject the null hypothesis $\left(\mathrm{H}_{0}\right)$ and accept the alternative hypothesis $\left(\mathrm{H}_{1}\right)$.

We therefore reject the null hypothesis $\left(\mathrm{H}_{0}\right)$ and accept the alternative hypothesis $\left(\mathrm{H}_{1}\right)$

\subsubsection{Hypothesis two}

$\mathrm{H}_{0}$ : There is significant relationship between technologydriven appraisal system with multi-sourced appraisal data and high level of employees'job satisfaction.

$H_{1}:$ There is no significant relationship between technologydriven appraisal system with multi-sourced appraisal data and high level of employees'job satisfaction.

Relevant in testing hypothesis two is question 3 of the questionnaire.

From the chi-squared analysis in table $4, \mathrm{X}^{2}=\left[\left(\mathrm{O}_{\mathrm{i}}-\mathrm{E}_{\mathrm{i}}\right)^{2} / \mathrm{E}^{\mathrm{i}}\right]$ for question 2 is $\mathbf{2 4 8 . 3 4}$

Our degree of freedom (d.f.) $=(n-1)=4$ and our level of significance $(\alpha)$ is 0.05 Decision

Tabulated value of $\mathrm{X}^{2}\left(\mathrm{X}_{2} \mathrm{Tab}\right)$ at 4 d.f. and 0.05 level of significance $=\mathbf{9 . 4 8 8}$

The Calculated value of $\mathrm{X}^{2}\left(\mathrm{X}^{2} \mathrm{Cal}\right)=\mathbf{2 4 8 . 3 4}$

$\mathrm{X}^{2} \mathrm{Cal}>\mathrm{X}^{2} \mathrm{Tab}$

The decision rules states that if $\mathbf{X}^{\mathbf{2}} \mathbf{C a l}$ is greater than $\mathbf{X}^{\mathbf{2}} \mathbf{T a b}$, we should reject the null hypothesis $\left(\mathrm{H}_{0}\right)$ and accept the alternative hypothesis $\left(\mathrm{H}_{1}\right)$.

We therefore reject the null hypothesis $\left(\mathrm{H}_{0}\right)$ and accept the alternative hypothesis $\left(\mathrm{H}_{1}\right)$. 


\subsubsection{Hypothesis three}

\section{$\mathrm{H}_{0}$ : Use of technology-driven appraisal system minimizes} errors in the appraisal process.

\section{$\mathrm{H}_{1}$ : Use of technology-driven appraisal system does not minimize errors in the appraisal process.}

Relevant in testing hypothesis three is question 3 of the questionnaire.

From the chi-squared analysis in table $4, \mathrm{X}^{2}=\left[\left(\mathrm{O}_{\mathrm{i}}-\mathrm{E}_{\mathrm{i}}\right) 2 / \mathrm{E}_{\mathrm{i}}\right]$ for question 2 is $\mathbf{3 3 3 . 3 6}$

Our degree of freedom (d.f.) $=(n-1)=4$ and our level of significance $(\alpha)$ is 0.05

\section{Decision}

Tabulated value of $\mathrm{X}^{2}\left(\mathrm{X}^{2} \mathrm{Tab}\right)$ at 4 d.f. and 0.05 level of significance $=\mathbf{9 . 4 8 8}$

The Calculated value of $X^{2}\left(X^{2} \mathrm{Cal}\right)=\mathbf{3 3 3 . 3 6}$

$\mathrm{X}^{2} \mathrm{Cal}>\mathrm{X}^{2} \mathrm{Tab}$

The decision rules states that if $\mathrm{X}^{2} \mathrm{Cal}$ is greater than $\mathrm{X}^{2} \mathrm{Tab}$, we should reject the null hypothesis $\left(\mathrm{H}_{0}\right)$ and accept the alternative hypothesis $\left(\mathrm{H}_{1}\right)$.

We therefore reject the null hypothesis $\left(\mathrm{H}_{0}\right)$ and accept the alternative hypothesis $\left(\mathrm{H}_{1}\right)$.

\section{DISCUSSION}

\subsection{Categorization of Existing Performance Systems}

Previous attempts at conducting performance appraisal in organizations could be categorized into the following:

\section{(1) Traditional systems.}

As outlined by Rudman [8], some of the traditional appraisal methods include:

(a) Comparison or ranking method: Comparison or ranking methods require each person - or some characteristic of a person or a person's performance - to be compared with every other employee, with the results then being used to produce a rank order for all the employees. These methods are simple and easily understood, quick and inexpensive to implement and can achieve relatively high reliability, but they are not often used for performance planning and review. There are some major problems with this method. Comparisons are usually made on the basis of a single behavioural dimension (e.g. 'reliability') or job-related characteristic (e.g. 'product knowledge') or some overall assessment (e.g. 'value to the organization'). Unless these descriptors are given specific definitions, there is a risk that different reviewers will apply different standards in assessing relative worth, and the rank order will lack a defensible rationale. They are cumbersome when large numbers of employees are involved, or when more than one manager has to contribute to the ranking process, or when a number of characteristics need to be ranked. These methods are also subject to bias and discrimination on the part of those who decide the rankings. These would lead to employees' dissatisfaction and erode the intended gains of the appraisal process [8].

(b) Standards-based Reviews: Like comparison or ranking methods, standards-based review methods concentrate on an employee's characteristics or traits, rather than the person's actual performance or behaviour. These methods include application of critical incidents interviews, essays and narrative appraisals, use of checklist in performance reviews, application of forced choice reviews, use of rating scales, behaviourally anchored ratings scales (BARS), behavioural observed scales (BOS). The obvious problems with narrative methods are questions of comprehensiveness and difficulties of bias. Rater error is a problem, especially the halo effect where one attribute or incident dominates the overall rating. Managers seem to find it difficult to spread their ratings across the entire scale, leading to the central tendency problem where ratings are bunched around the middle of the scale, or a skewed distribution where all the ratings are too high or too low. The traditional systems of appraisal $[7$ are judgmental in nature and prone to psychometric errors - errors in measurement that occur because of the psychological predisposition or make-up of the assessor [8]. The unfortunate fact about psychometric errors is that most assessors are not aware that they are liable to such errors [8]. Psychometric errors include but are not limited to halo effect - the tendency for ratings and assessments to be influenced by one or two positive attributes of the individual, resulting in an overall favourable assessment that would not necessarily be supported by a careful consideration of all relevant factors; horns effect - an overall unfavourable assessment resulting from the undue influence of one or two negative factors; central tendency error - caused by psychological bias against using extremes and as such assessors avoid both ends of a rating scale in making their assessments; leniency error ratings that are too high or too low in terms of employees' actual performance and will produce an inaccurate or skewed distribution of assessments; recency error - a tendency to judge people on the basis of a recent incident or performance that might not be typical of the whole review period, or on the basis of a single factor or impression; contrast error - where an assessor gives an employee an unjustifiably high or low rating in contrast to a very low or high rating given to the previous employee assessed; bias/prejudice - a conscious or an unconscious discrimination set off by age, race, sex, cultural origins, appearance, marital status, social position or personal habits and/or personal judgments about an employee that have no relevance to job performance; logical error occurs when characteristics or factors that appear to be logically related are given similar ratings, even though they are not actually linked; attributional error - where an assessor attributes an employee's lack of goal achievement to personal deficiencies and pays insufficient attention to other factors [8].

(c) Result-oriented Reviews or Management By Objectives: One way to approach measuring performance, popularized by management guru Peter Drucker, is Management by Objectives. Management by Objectives (MBO) is the best known of the results-oriented methods of performance planning and review and, in some form, probably the most frequently used approach to performance planning and review. MBO has been a feature of organizational life since it was popularized in the 1950s by Peter Drucker, John Humble and others as a replacement for the traditional bureaucratic or job-holding approach to employment [8]. In simple terms, MBO is a target-setting or results-oriented approach to performance management. It recognizes that employees perform better when they have targets, and even better when they have participated in setting those targets [8]. While this approach is readily applied to jobs in, say, production or sales - where specifying targets and measuring performance in quantifiable terms is relatively straightforward - it can be more difficult in roles where quality is more 
important than quantity, or where the prime purpose is to provide support or service to others [8].

(d) Competency-based Reviews: Competency-based approaches to employee assessment have developed out of the growing use of competency-based approaches in many areas of human resources management, all of which are affected by the continuing lack of consensus over the 'competency' concept. If we accept that competency is 'the set of behaviour patterns that the incumbent needs to bring to a position in order to perform its tasks and functions with competence' [7], then it is clear that competency-based approaches to appraisal are concerned less with what employees achieve on the job than with what they have the capability or competency to do. In other words, these methods assess the individual's potential to perform rather than the actual performance [8]. Most competency based-reviews make use of general statements of competences which is applied across an occupation or an organization. Though less time and resources are needed to develop generic competences, this advantage is usually eroded if the descriptions are not sufficiently specific to a particular role or occupation. Competency statements can be used for the assessment of current performance but are better used to assess employees' abilities and development needs than the results they achieve. However, using competences to assess only the current situation seems to be a waste of significant amounts of analysis. Competency-based assessment, therefore, is most useful as a developmental tool - a kind of map that guides individuals from where they are at present to where they need to be in the future. But that map will need to change as individual employees make progress through their organizational and job careers [7].

\section{(2) Automated systems}

(a) Analytic hierarchy process (AHP)-based systems. Several researches have been done to tailor the existing traditional or manual appraisal process to be more accurate and objective. Islama and Rasad [9] created an AHP-based evaluating process based on weighted criteria to combat such problems as favouritism and prejudice. The criteria were structured around quantity/quality of work, planning/organization, team work/cooperation and more weighted by importance by the Human Resource Managers. Each employee was given a rating on their performance on each weighted criteria and an overall weighting score was calculated. This system remains partially manual and is heavily reliant on the Human Resource Department's willingness to cooperate.

(b) Application of time card system and Internet of things (IoT). To address the challenges encountered by the AHPbased systems, a system that is automatic and accurate was devised by Sharma and Hosein [10]. This was a time card system with a card reader that recorded employees' entries and exits. The difference in hours worked by an employee as well as their minutes was calculated and output as reports. The system makes use of IoT based systems to automatically gather accurate data that feeds into an evaluation algorithm. The attendance dataset used in their research was derived from radio-frequency identification (RFID) scanners for recording clock-in and clock-out times. While IoT and RFID devices do not eliminate all methods of data tampering, they discourage a variety of them. The use of this system created some challenges - the employee welfare challenges. For instance, it did not take into consideration days of approved absenteeism from work based on health or other human factor challenges. There was no way of measuring employee daily task output and competency skills. The system merely calculates employees' performance based on data from clockin and clock-out registers.

(c) Application of game theory in appraisal systems. Kaur and Sood [11] in their work "A Game Theoretic Approach for an IoT-Based Automated Employee Performance Evaluation" proposes a game theoretic approach for an Internet of things based performance evaluation of the employees in industry. The ubiquity of the sensing capabilities of IoT devices enables continuous supervision of industrial employees due to which the proposed system is able to evaluate the performance of employees regularly. Moreover, the learning capabilities of the game model replace manual systems with an automated system. In their system, the data collected by IoT devices are used to detect the actions of every employee in industry. Based upon the employee actions, their performance is valuated. The game model is then used to take decisions for employees. The proposed system uses the pay-forperformance (pfp) system for decision making. The pfp, also known as gain sharing, rewards the employees who perform better. On the other hand, a penalty is imposed on the employee who works against the industry's policies. Figure 2 below shows the workflow of their proposed system in which, initially, various IoT devices collect data from the industrial infrastructure as well as from employees. Various employees activities were then detected from the sensor measurements of IoT devices to form activity sets. The participation of each employee in each activity was determined using collocation mining which gives the performance of employees in industry. Game-based automated decisions were then taken by the industry using performance information of the employees. The detailed description of their proposed system is as follows.

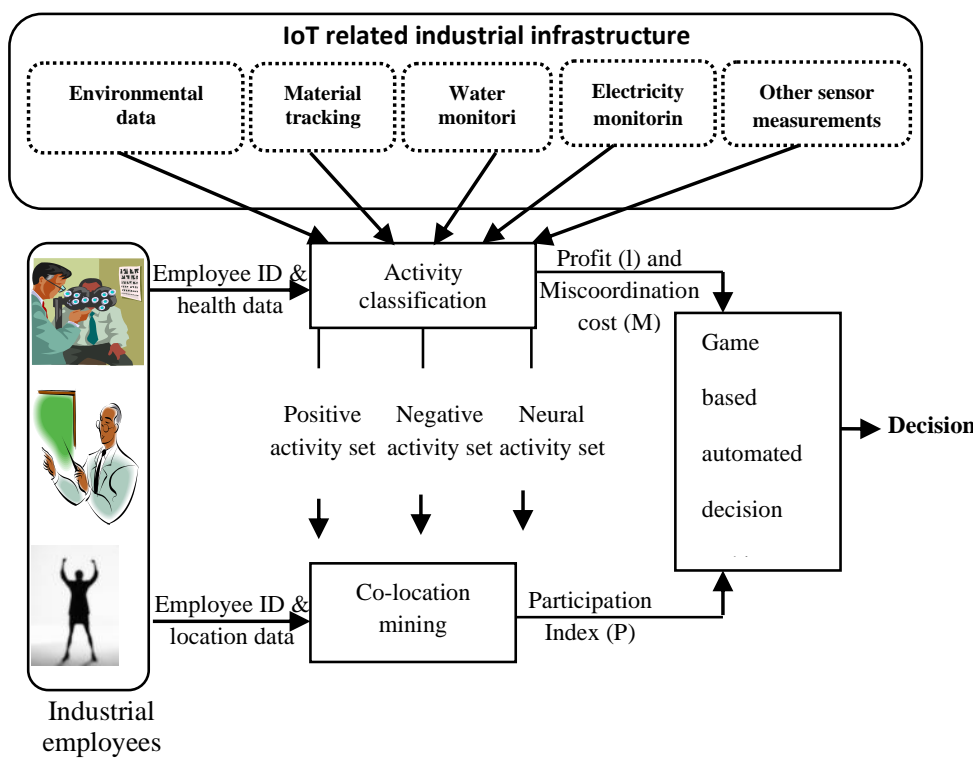

Figure 2. Workflow of Kaur and Sood proposed system

Source [11]

The data collected by sensor nodes and other IoT hardware devices are used to depict the employee activities in industry. The industrial activities of employees are classified into three types, namely, positive, negative, and neural activities. The positive activities are profitable to industry, while the negative activities lead to loss in industry. The neural activities are 
necessary for proper working of an industry and are not associated with any profit or loss. The set consisting of all positive activities is termed as positive activity set. Similar is the case for negative and neural activity sets. The system groups employees' work performance into three extreme categories:

(a) $A_{P}$ - employees with higher participation in positive work activities and who must be rewarded;

(b) $\mathrm{A}_{\mathrm{N}}$ - employees with higher participation in negative work activities and who must be punished; and

(c) Ao - employees who neither participated in higher work activities nor participated in negative work activities and who must neither be rewarded nor punished.

This system has its own flaws. Assessments of employees are not based on competency skills and the system also fails to capture employees' daily task outputs as part of performance appraisal. There is no discrete ranking of employees' work output and organizational behaviour as to determine the highest scored employee and the lowest scored employee within a given assessment period.

\section{(d) Application of fuzzy based methods}

Several work were done on employee performance appraisal using fuzzy set theory. Moon et al. [12] proposed a methodology utilizing fuzzy set theory and electronic nominal group technology for multi-criteria assessment in the group decision-making of promotion screening; Researched have demonstrated [13] that fuzzy set theory could be successfully used to solve multiple criteria problems. This is because in many circumstances, appraiser tends to use vaguely defined qualitative criteria in evaluating the performance of their subordinates. Therefore, it creates difficulty for appraiser to precisely quantify the score of each candidate. The fuzzy system of appraisal emphasizes on the mapping of uncertainty data in performance measurement system into fuzzy values which consists of labels and confidence values. The mapping process is essential since if erroneous membership function and rules were chosen, it yields a flawed output. In the appraisal process using the fuzzy logic method, the performance of the appraisee usually involves the measurement of ability, competence, job behaviors, and skills, which are fuzzy concepts that may be captured during the performance appraisal process [15]. The Fuzzy appraisal evaluation system is usually made of the following components:

(a) The evaluation's criteria;

(b) Existing performance evaluation tool;

(c) Crisp input values;

(d) Fuzzy values; and

(e) Crisp output values.

The crisp input values are observed from existing evaluation tool. The input values, which are in the form crisp values, are processed through fuzzification phase, fuzzy inference phase, and defuzzification phase in order to convert fuzzy values into crisp output values for employees' performance assessment. The process is shown in the figure 3 below.

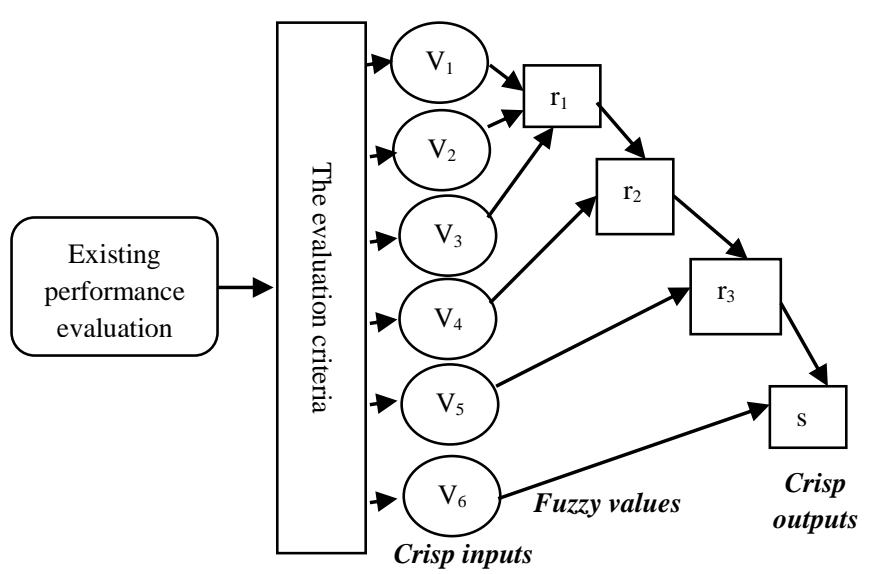

Figure 3. Fuzzy appraisal evaluation system

This system of appraisal has its own shortcomings. The validity of the performance data and the rating scale is not guaranteed by the fuzzy system. In fact the fuzzy system itself depends on the availability of the performance data and the rating scale which are fed as crisp inputs into the fuzzy system. The success of the Fuzzy system of performance appraisal is heavily reliant on the experience of selecting what constitutes membership functions and rules. If erroneous membership function and rules were chosen, it yields a flawed output. Setting exact fuzzy rules and membership functions is a difficult task. Validation and verification of a fuzzy knowledge based system needs extensive testing with hardware. Fussy systems are not based on measurable task outputs but on fuzzy or crisp qualitative employee appraisal skills and so do not measure a critical part of modern organizational performance criteria.

\section{(e) Online performance appraisal software}

Several recent software have also been developed to take care of employee performance appraisal processes. These software include but are not limited to the following: Trakstar performance appraisal software, Bamboo HR, Engagedly performance appraisal software, Ultipro performance appraisal and Workday performance appraisal. Most of the available online appraisal solutions limited their performance measures to competencies only- other performance metrics emphasized by literature were ignored. The existing online appraisal systems also made use of generic ratings for all workers irrespective of their roles or positions within their organizations. This approach overlooked some important performance criteria there were relevant to particular jobs, and included other criteria that were irrelevant to others. These systems also did not consider the smart application of biometrics in employee appraisals and therefore could not uniquely recall a personnel impersonating another or tampering with employee appraisal information.

\subsection{Known metrics of performance appraisal process}

Performance appraisal by its various definitions [1], [2], [3], [4], [5] suggests a system of measurement. The challenge of the appraisal process is in determining what exactly should be measured and how it should be measured in order to minimize error and increase employees' satisfaction with the outcome. Therefore, the creation of performance criteria is an important 
requirement towards performance appraisal. Although, it is a well known fact that there are no perfect appraisal systems, it is nonetheless important to emphasize that appraisal is a process, and like any other process, it has inputs, outputs, objectives, and owner(s). Therefore the appraisal process should be measurable and should be applied to bring results to its owner(s). Better appraisal process yields better appraisal outcome, and vice versa. The danger of not having an effective process is that the outcome leads to employees' job dissatisfaction, reduces employees' organizational commitments, lowers employees' moral and reduces organizational citizenship behaviours amongst employees. This is shown in figure 4 below.

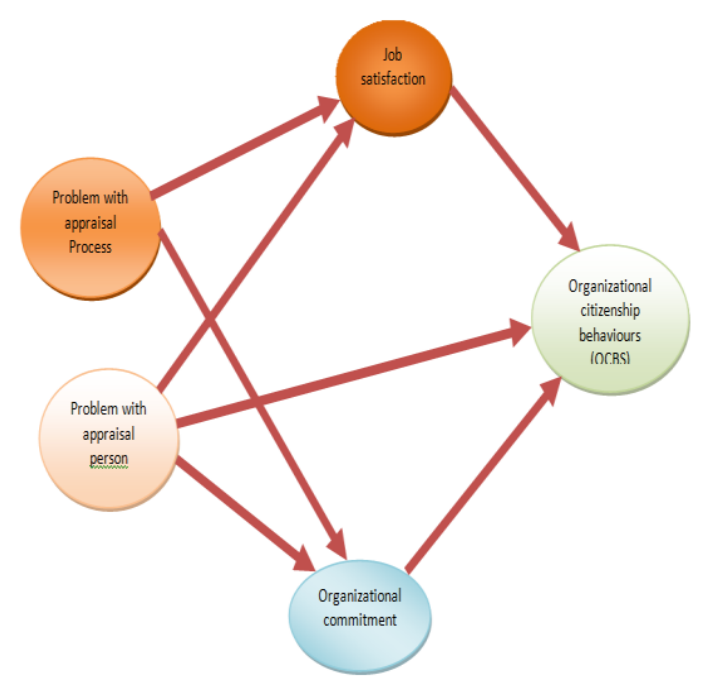

Figure 4. Relationship between appraisal outcome and OCB, and job commitment.

Source: [15]

To buttress the importance of performance measurement in organizations, [16] stated that rewards are indeed extremely powerful, and people will naturally tend to do the things for which they are rewarded, but no matter how important and powerful rewards are, they are no better than the measurement system they are based on. Organizations are conglomerations of many systems. Measurement is actually the most fundamental system of all. When the measurement system works well, management tends to manage (and reward) the right things- and the desired results will occur [16]. The wrong measures tend to trigger the wrong activities - because they represent what people see. Then these wrong activities generate the wrong results - no matter how well-executed the activities are. Most individuals and organizations do not get what they want because they do not measure what they really want [16].

Performance measures can be viewed as objective or subjective. The objective measures can be observed - for example, the number of items sold or the number of invoices processed can be counted. Objective performance measures include production data (e.g. units produced, number of errors, etc) and employment data (e.g. number of incidents, absences, tardiness, etc). Objective measures are usually, but not always result-based. These variables directly define the goals of the organization and, therefore, sometimes are outside the employee's control. Objective measures of job performance involve counts of various work-related behaviours. Some common objective job performance measures include [17]:

- Absenteeism (number of days absent)

- Accidents (number of accidents)

- Incidents at work (number of incidents / assaults /etc)

- Lateness (days late)

- Meeting deadlines.

Objective measures can be relatively quick and easy to obtain (given good organizational recordkeeping).

However, it can be unwise to place too much emphasis on these types of objective measures. An exclusive focus on results/outcomes may mask factors that impact on workers' performance that are beyond their control (e.g., client workload) [19]. Subjective measures require judgment on the part of the evaluator and are more difficult to determine. They are also prone to biases and errors. One example of a subjective measure is a supervisor's ratings of an employee's "attitude," which cannot be seen directly. Subjective measures rely on the judgment of an appraiser (self, co-workers, or supervisor). Subjective assessments are commonly used in performance appraisals and often involve the use of rating scales. Subjective assessments are more likely to provide accurate performance appraisals when: the behaviours and outcomes being assessed are stated in clear behavioural terms; the worker understands the measures (e.g., rating scales) being used to evaluate their performance, and agree that the measures are fair and accurate (i.e., measures what it is

supposed to); and measurement is as brief as possible whilst addressing essential behaviours and outcomes (frustration with long and unwieldy questionnaires may introduce error in responses)[18]. Consequently, both objective and subjective measures should be used carefully. Sources of performance appraisal data are shown in figure 5 below.

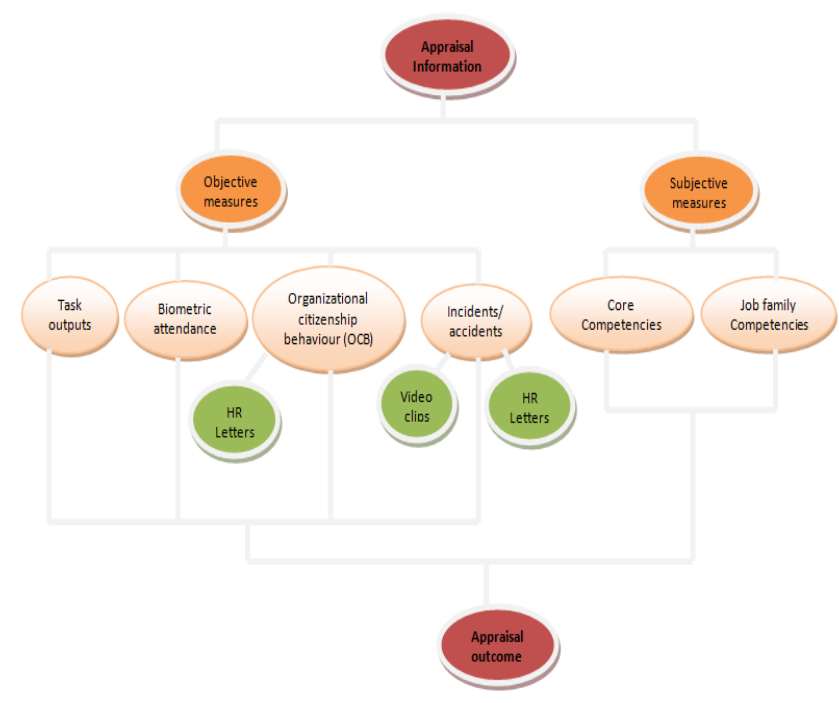

Figure 5. Sources of appraisal information

Measurement provides the basis for providing and generating feedback, and thus can build the platform for further success or identify why things are going less well so that corrective 
actions can be taken. Therefore what gets measured in the appraisal process? Measure the wrong things perhaps because they are easy to measure, and an entire appraisal system can fall into disrepute. In making overall performance assessments, we should ensure that all aspects of performance are taken into account and not just those areas where targets for improvement or development were set [8] As Drucker [16] puts it the measurements which give us productivity for the manual worker, such as the number of pieces turned out per hour or per dollar of wage, are irrelevant if applied to the knowledge worker. Drucker [16] goes on to further state that a productivity measurement is the best yardstick for comparing managements of different units within an enterprise, and for comparing managements of different enterprises. This is because productivity includes all the efforts the enterprise contributes; it excludes everything it does not control. According to Drucker [16], productivity is the first test of management's competence. According to Drucker [16], measurement should be used to make selfcontrol possible and should not be abused to control people from the outside and above - that is, to dominate them. Drucker [16] further stated that as long measurements are abused as a tool of control, measuring will remain the weakest area in the manager's performance. In furtherance to his argument, Drucker [16] stated that for a manager to be able to control his own performance, he needs to know more than what his goals are. He must be able to measure his performance and results against the goals. The measurements need not be rigidly quantitative; nor need they be exact, but they have to be clear, simple, rational, relevant and direct attention and efforts where they should go.

Performance measures that leave out some important job duties are considered deficient. For example, measurement of an employment interviewer's performance is likely to be deficient if it evaluates only the number of applicants hired and not the quality of those hired or how long those hired stay at the company. On the other hand, including irrelevant criteria in performance measures contaminates the measures. For example, appearance might be a contaminating criterion in measuring the performance of a telemarketing sales representative whom customers never see. Managers need to guard against using deficient or contaminated performance measures. Overemphasis on one or two criteria also can lead to problems as other important areas may be ignored. In addition, cheating can become an issue when goals are set to support such criteria because individuals might act unethically to reach objectives, especially when the objectives are linked to specific rewards [18]. As shown in figure 5 above, utilizing all know sources of appraisal data in measuring appraisal outcome is ideal. To solve the problem of what should be measured; Rudman [8] suggested that organizations combine various methods and techniques in developing performance appraisal systems. For example, a system might usefully combine $\mathrm{MBO}$, which is a way to determine what an employee is expected to do, with behavioural rating concerned with how an employee carries out job requirements or behave on the job [8]. Some scholars argue that perceived justice appears to be an essential mechanism through which appraisals affect employees' reactions (e.g., Erdogan [27] Greenberg [23]) and such argument has received considerable attention in the performance appraisal literature [18]. There are two types of justice described in the literature of justice and fairness that are involved in the performance appraisal process: distributive justice and procedural justice [18].
Levels of perceived procedural justice are positively related to important organizational outcomes such as organizational citizenship behaviour [24], [22], [25], [26], [41], [27]; trust in leadership [28], [29], [27]); organizational commitment; job satisfaction; and performance [30], [31]. Folger et al. [41] argue that a comprehensive model for a procedurally just performance appraisal systems should include fair hearing and judgment based on evidence among other variables. Support for this model has been found in other studies [27], [33], [34]. These studies found that characteristics of the due process appraisal (fair hearing and evidence-based criteria) were associated with perceived procedural justice. In addition, Poon [33] found that when employees perceived the performance appraisal process as manipulative and skewed by the political interests of the raters (as opposed to the due process), they demonstrated less satisfaction and higher intention to quit their jobs.

\subsection{Design of an effective employee performance appraisal system}

Van and Schodl [21] states that if the main purpose of a performance appraisal process is to increase performance, then an effective performance appraisal system would be one that achieves this purpose. An effective appraisal system is dependent on a number of factors and these include: accuracy of ratings, source of appraisal data and perceived justice in the process. An effective appraisal system as described by Skinner et al. [18], involves among others: the appraisal instrument, the job analysis conducted to identify the appropriate criteria against which to establish standards for evaluating performance, and establishing the validity and reliability of the methods used. Regular monitoring of performance is another essential element of an effective appraisal process. Performance monitoring is a term applied to a variety of workplace practices that concern the collection of employee work performance data [18]. An effective performance appraisal should not be limited to a formal event occurring once or twice a year but should be a continuous process of day-to-day monitoring, feedback and review that provides first hand information to help identify performances shortfall so as to correct them promptly [18]. An effective appraisal system should be technology-driven. The use of technology in performance management has the potential to increase productivity, and enhance competitiveness. A performance appraisal system that uses technology to automate processes can provide many advantages to organizations, so human resource professionals should consider utilizing electronic methods to facilitate the manner in which appraisal procedures are administered and managed [18]. It is believed that appraisal satisfaction is a key concept that is central to any discussion of technology to be adopted in the appraisal process. Technology contributes to performance management and thus to appraisal satisfaction in two primary ways: technology facilitates measuring an individual's performance via computer monitoring activities and two, technology becomes a tool to facilitate the process of capturing appraisal data and generating performance feedback. An effective appraisal system should utilize multisource appraisal data in rating employees' performance. To enhance perception of system fairness, practitioners should find a way to balance quantitative performance data with 
qualitative performance data. Key performance job criteria should be as outlined in table 3 below [18].

Table 3. Key performance job criteria

\begin{tabular}{|l|l|}
\hline Competencies & $\begin{array}{l}\text { Knowledge, skills, and abilities } \\
\text { relevant to performance }\end{array}$ \\
\hline Behaviours & $\begin{array}{l}\text { Related to individual } \\
\text { productivity such as leadership } \\
\text { styles, analytical skills, etc. } \\
\text { Specific actions conducted/or } \\
\text { tasks performed. }\end{array}$ \\
\cline { 2 - 2 } & $\begin{array}{l}\text { Organizational citizenship } \\
\text { behaviour (OCB) - actions that are } \\
\text { over and above usual job } \\
\text { responsibilities. }\end{array}$ \\
\cline { 2 - 3 } & $\begin{array}{l}\text { Counterproductive work } \\
\text { behaviours such as assaults, } \\
\text { abuse of customers, etc. }\end{array}$ \\
\hline Traits & $\begin{array}{l}\text { Relating to individual's way of } \\
\text { life such as "a good attitude", } \\
\text { showing "confidence", being } \\
\text { "dependable", etc. }\end{array}$ \\
\hline Results / \\
outcomes & $\begin{array}{l}\text { Outputs, quantifiable results, } \\
\text { measurable outcomes and } \\
\text { achievements, objectives attained, } \\
\text { incidents, absences, etc. }\end{array}$ \\
\hline
\end{tabular}

Source: [18]

Other scholars argue that: an effective appraisal system should ensure that the appraisal data is highly secured and that the source data is validly collected. These can be achieved through the use of password secured systems and the application of biometrics in capturing attendance data; an effective appraisal system should permit greater span of control by facilitating accurate collection of performance data without requiring managers to spend significant time observing each individual worker's actual job performance; an effective appraisal system should be multi-rater based. The 360-degree feedback system should be part of the appraisal system. There are several advantages to using this system compared to a single source of performance information [26]. First, 360-degree feedback systems result in improved reliability of performance information because it originates from multiple sources and not just one source. Second, they consider a broader range of performance information, which is particularly useful in terms of minimizing criterion deficiency. Third, they usually include information not only on task performance but also on contextual performance and counterproductive work behaviours, which are all important given the multidimensional nature of performance. Finally, because multiple sources and individuals are involved, 360-degree feedback systems have great potential to decrease biases particularly compared to a system involving a single source of information.

Acknowledging the fact that a performance appraisal system should be automatic and data-driven, what we propose in this study is a system that uses expanded range of performance tools to capture data that involves employees task outputs (quantity of work/period, quality of work/period), number of organizational citizenship behaviours (OCBs), number of incidents at work, number of errors, number of accidents at work, accurate data on staff attendance, absenteeism, hours worked and competencies in order to balance employees quantitative-qualitative performance data or put differently in order to give validity to the instrument of performance measurement; a system that does not use a generic rating form for all workers irrespective of their roles or positions within the organization but uses job family competencies applicable and relevant to employees' roles and positions in the organization; and a system that provides a convenient way in which fingerprint authentication can be applied in employee appraisal system to avoid unwanted tampering with the system's data. The proposed is system design is shown in figure 6 below.

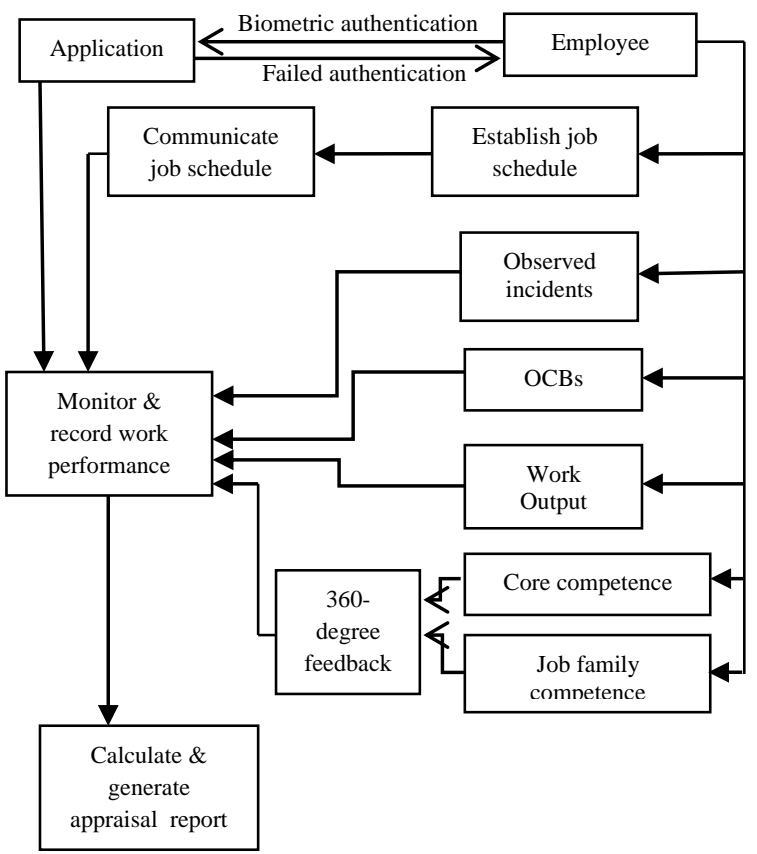

Figure 6. Employee performance appraisal system design

\section{CONCLUSION}

The study revealed that an effective performance appraisal system depends heavily on perceived organizational justice, the accuracy of the instruments of rating used, the sources of the appraisal data, the content of job performance criteria, and the type of technology that drives the process. It further reveals that an effective appraisal system should be technologically-driven, it should have large span of control as data-capture is automated, it should be multi-rated, appraisal information should be multi-sourced, it should be evidencebased, it should be accurate, reliable and should promote organizational justice and it should be able to utilize all known metrics of performance measurement in the appraisal process. 


\section{REFERENCES}

[1] Palaiologos, A., Papazekos, P. and Panayotopoulou, L. 2011. "Organizational justice and employee satisfaction in performance appraisal", Journal of European Industrial Training, Vol. 35 No. 8, pp. 826-840.

[2] DeNisi A. and Smith C. E. 2014 "A. Performance Appraisal, Performance Management, and Firm-level Performance: A Review, a Proposed Model, and new Directions for Future Research". The Academy of Management Annals, 8(1), 127179.

[3] DeNisi A. S. 2000. Performance Appraisal and Performance Management. Multilevel Theory, Research, and Methods in Organizations: Foundations, Extensions and new Directions. San Francisco, CA: Jossey-Bass, 121-156.

[4] Coens T. and Jenkins M.. 00. Abolishing Performance Appraisal. Why they Backfire and what to do Instead. San Francisco: Berrett-Koehler Publishers.

[5] Boachie-Mensah F. O. and Seidu P. A. 12. "Employees' Perception of Performance Appraisal System: A Case Study". International Journal of Business and Management, 7(2), 73.

[6] Ellington J. K and Wilson M. A. 16. "The performance appraisal milieu: a multilevel analysis of context effects in performance ratings". Journal of Business and Psychology, 1-14.

[7] Vicky G., Performance Appraisal.. 02. Loss Control Services, Texas Association of Counties.

[8] Rudman R., Performance planning and review. Making employee appraisal work (2nd Edition). New Zealand: Allen \& Unwin Publishing, 03.

[9] Islama R. and Rasad S. 06 "Employee Performance Evaluation by the AHP: A Case Study. Asia Pacific Management Review, Vol. 11,pp. 163-176, 01.

[10] Sharma N. and Hosein P. . "A Comparison of Data-driven and traditional approaches to employee performance assessment. International Conference on Intelligent Data Science Technologies and Applications (IDSTA)", , pp. 34-41.

[11] Kaur N. and Sood S. K.. 17. "A game theoretic approach for an iot-based automated employee performance evaluation". IEEE Systems Journal, Vol. 11, no. 3, pp. 1385-1394.

[12] Moon C., Lee J., Jeong C., Lee J., Park S. and Lim S. 07. “An Implementation Case for the Performance Appraisal and Promotion Ranking, in Proceedings of the", IEEE International Conference on Systems, Man and Cybernetics, Montréal, Canada, 7-10.

[13] Jing R.C, Cheng C. H. and Chen L. S. 07. "A Fuzzy-based Military Officer Performance Appraisal System". Applied Soft Computing, Vol. 7, Issue 3

[14] Shaout, A., \& Yousif, M., K. 14. Employee performance appraisal system using fuzzy logic. International Journal of Computer Science and

Information Technology, Vol 6, No 4, pp 1-19, August 14
[15] Na-Nan K., Kanthong S., Joungtrakul J. and Smith I. D. "Mediating Effects of Job Satisfaction and Organizational Commitment between Problems with Performance Appraisal and Organizational Citizenship Behaviour". Journal of Open Innovation: Technology, Market and Complexity, Vol. 6, issue 3.

[16] Drucker P. F. 1986. Management: Tasks, Responsibilities, Practices. New York: Truman Talley Books/E.P. Dulton.

[17] Spector P. E. 00. Industrial and Organizational Psychology: Research and Practice (2nd ed.). New York: Wiley.

[18] Skinner N., Roche A., O'Connor J., Polland Y. and Todd C. 05. Workforce Development TIPS (Theory into Practice Strategies):A Resource Kit for the Alcohol and other Drug Field., S..A.: National Centre for Education and Training in Addiction.

[19] Mathis R. L. And Jackson J. H. 10. Human Resource Management (13th edition). Ohio: South-Western Cengage Learning.

[20] Mullins L.J. 05. "Management and Organizational Behaviour". London: Financial Times Management.

[21] Van D. D. and Schodl M. M. 2015. "Performance Appraisal and Evaluation, In James D. Wright (editor-in-chief)", International Encyclopaedia of the Social \& Behavioural Scieces, 2nd edition, Vol. 17, pp. 716-721. Oxford: Elsevier Ltd.

[22] Moorman R. H., Balkely G. L., Neihoff B. P. 1998. "Does Perceived Organizational Support Mediate the Relationship between Procedural Justice and Organizational Citizenship Behavior?'Academy of Mana gement Journal 41 (3), 351-357.

[23] Greenberg J. 1986. "Determinants of Perceived Fairness of Performance Evaluation". Journal of Applied Psychology 71 (2), 340-342.

[24] Ball G. A., Trevino L. K., Sims Jr. H. P. 1994. "Just and Unjust Punishment: Influences on Subordinate Performance and Citizenship". Academy of Management Journal 37 (2), 299 322.

[25] Organ D. W., Podsakoff P. M., Mackenzie S. B. 2006. Organizational Citizenship Behaviour: Its Nature, Antecedents and Consequences. Thousand Oaks, CA: Sage.

[26] Skarlicki D. P. and Latham G. P. 1996. "Increasing Citizenship within a Union: A Test of Organizational Justice Theory". Journal of Applied Psychology81 (2), 161-169.

[27] Whiting S. W., Posdakoff P., and Pierce J. R. 2008. "Effects of Task , Helping, Voice and Organizational Loyalty on Performance Appraisal Ratings". Journal of Applied Psychology 93 (1), 125-139.

[28] Barling J. and Phillips M. 1993. "Interactional, Formal and Distributive Justice in the Workplace: An Exploratory Study". Journal of Psychology 127 (6), 649-656.

[29] Folger R. and Konovsky M. A. 1989. "Effects of Procedural and Distributive Justice on Reactions to Pay Raise Decisions". Academy of Management Journal 32, 115-130. 
International Journal of Computer Applications Technology and Research

Volume 10-Issue 11, 237-247, 2021, ISSN:-2319-8656

[30] Colquitt J. A., Conlon D. E., Wesson M. J., Porter C. O. L.H., and $\mathrm{Ng} \mathrm{K}$. Y. 2001. "Justice at the Millennium: A Meta-

analytic Review of 25 years of Organizational Justice

Research". of Applied Psychology 86 (3), 425-445.

[31] Korsgaard M. A., Schweiger D. M., Sapienza H. J.1995. "Building Commitment, Attachment and Trust in Strategic Decision-making Teams: The Role of Procedural Justice". Academy of Management Journal, 38(1), 60-84.

[32] Folger R., Konovsky M. A., and Cropanzano R. 1992. "A Due Process Metaphor for Performance Appraisal. In: Staw, B. M., Cummings, L. L. (Eds.)", Research in Organizational Behaviour, vol. 14. JAI press, pp. 129-177.

[33] Poon J. M. L. 2004. "Effects of Performance Appraisal Politics on Job Satisfaction and Turnover Intention". Personnel Review 33 (3), 322-334.

[34] Taylor M. S., Masterson S. S., Renard M. K., and Tracy K. B. 1998. 'Managers' Reactions to Procedurally Just Performance Management Systems". Academy of Management Journal 41 (5), 568-579. 